\title{
Can Lonely Riders Become Three Musketeers? Creating Effective Joint Operations among Farmers
}

\author{
Vidar Schei ${ }^{1}$, Bjørn G. Hansen ${ }^{1} \&$ Marcus O. Selart ${ }^{1}$ \\ ${ }^{1}$ Department of Strategy and Management, NHH Norwegian School of Economics, Norway \\ Correspondence: Vidar Schei, Department of Strategy and Management, NHH Norwegian School of Economics, \\ Breiviksveien 40, 5045 Bergen, Norway. Tel: 47-5595-9871. Fax: 47-559-5943. E-mail: vidar.schei@nhh.no
}

Received: October 16, 2012

Accepted: October 26, 2012

Online Published: November 8, 2012

doi:10.5539/ijbm.v7n23p45

URL: http://dx.doi.org/10.5539/ijbm.v7n23p45

\begin{abstract}
Individuals as well as organizations often need to work together to achieve economies of scale and scope. However, collaboration can be a challenge, and one example in which the potential benefit of cooperation has been difficult to realize are joint operations within the Norwegian farming industry. Thus, the purpose of this article is to illuminate why some of these joint operations fail while others prevail. We conducted in-depth interviews and gathered performance data in 10 joint farming operations, with our results revealing systematic patterns; those operations which had the highest level of performance and satisfaction had low levels of conflicts, whereas the others had higher level of conflicts. For the least successful operations, the conflicts were predominantly relational and typically approached with contention. Furthermore, the conflict patterns were systematically linked to team design and team planning, in which a balance and stability between partners, as well as a careful consideration of task issues and team issues, seem to be key variables.
\end{abstract}

Keywords: small joint operation, collaboration, formation, conflict, team, farming industry

\section{Introduction}

To help meet the challenges of an increasingly globalized competition, many individuals and organizations form various types of collaborative arrangements to achieve the benefits of scale and scope. One example of this is found in the Norwegian farming industry, where numerous farmers have established small joint operations that are typically formed between three to five farmers, in which quotas (in terms of how much milk they are allowed to produce), herds and farming lands are joined. Creating joint operations makes it possible to increase production capacity and carry greater investment costs, thereby taking advantage of complementary skills and resources.

However, a collaboration in joint operations does not guarantee success, and studies of strategic alliances indicate that approximately 50\% of joint ventures fail (Bamford, Ernst, \& Fubini, 2004; Rod, 2009), with similar numbers reported for teams in general (Mendzela, 1997). The challenges of collaboration in joint farming operations may be especially prominent because farmers have traditionally worked independently, and therefore have little experience with extensive and committed relationships. Unfortunately, few studies have addressed the challenges of such "lonely riders" trying to form effective collaborative operations, although these operations arguably need such knowledge the most.

Hence, the purpose of this paper is to illuminate why some joint farming operations fail while others prevail. Through in-depth interviews and analyses of performance data, our findings indicate a striking pattern between team planning, team design, conflict processes and the success of the joint operation in terms of performance and satisfaction. In short, aiming for a careful up-front discussion about the collaboration, in addition to a balanced structure between the members, seems to be linked to the avoidance of dysfunctional conflict processes, and in turn the accomplishment of the joint operation. 


\section{Effective Joint Operations}

Collaboration, in the form of joint operations in the Norwegian farming industry, is quite common; according to the State Agriculture Office, there were 1,684 joint operations in the dairy industry in 2010. In our study, we focus on joint operations with three or more members, as these operations are likely to pose the most prominent challenges. In some ways, these joint operations are comparable to a joint venture, i.e. two or more organizations start a new company together, but typically lack the joint ventures' linkage to a parent company. The joint operations are also comparable to a team, i.e. a group of people "interdependent with respect to information, resources and skills, and who seek to combine their efforts to reach a common goal" (Thompson, 2008 , p. 4), though in addition to a traditional team, are usually also a merger of (one-person) companies.

To better understand what creates effective joint operations, we will therefore rely on literature on both strategic alliances and on teams. Here, effectiveness or group outcome is primarily referred to as productivity and team satisfaction (Thompson, 2008), and in the context of this study is expected to be particularly affected by: (a) team planning (b) team design and (c) intragroup conflicts and conflict management. The conceptual model is summarized in Figure 1 and discussed below.

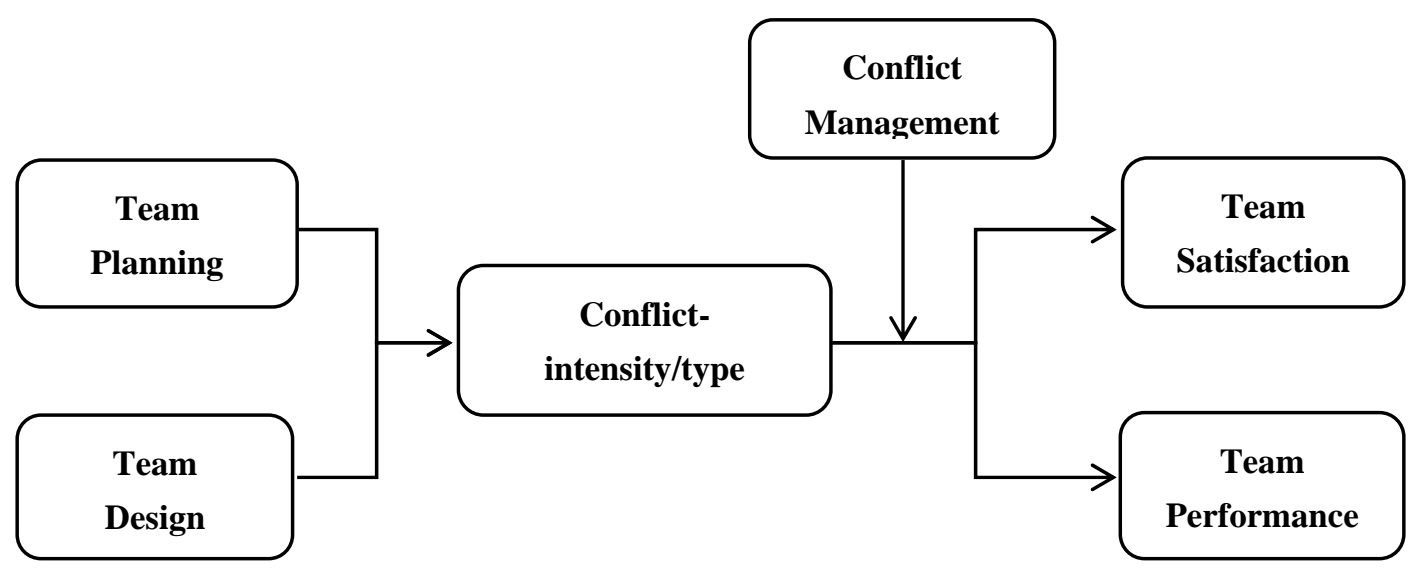

Figure 1. Model

\subsection{Team Planning}

The literature on strategic alliances focuses on the importance of planning the formation of collaboration (Bamford et al., 2004), with two factors being of particular importance in this phase, the choice of partner and subsequent negotiations. When it comes to choosing a partner, there are several factors that must be taken into consideration (Williams \& Lilley, 1993): 1) whether potential partners have goals that are consistent with your own, 2) if a partnership can activate gains in terms of economies of scale and/or complementarity, 3) the size between the companies should be relatively similar since differences easily create a dominant party, and 4) a potential partner should have sufficient financial strength, as the cash flows are often negative in the first phase of the collaboration. When it comes to negotiating with potential partners, Williams and Lilley (1993) emphasize the importance of discussing an adaptation of operating philosophies. Furthermore, the development of trust (cf. Wittmann, 2007) and mutual interdependency are important, in addition to clarifying how good communication between the parties can be assured. In summary, pre-collaboration planning consists of both a strategic and cultural assessment and adaptation (Haugland, 2004).

Team literature is particularly useful for understanding how newly established teams can lay a foundation for success. Mathieu and Rapp (2009) suggest focusing on two aspects in the start-up phase, taskwork and teamwork. Taskwork deals with what the team will do. Such a plan should contain the main objectives of the team, as well as a strategy for how the team will solve the tasks and how that strategy will be implemented (Mathieu \& Schulze, 2006). Teamwork provides a plan for how the team will work together, which should be adapted to the team's purpose and situation. An important element here is often the clarification of roles and responsibilities (Guttman, 2008; Katzenbach \& Smith, 1993a), while another is to clarify the norms and rules (Katzenbach \& Smith, 1993b). Norms often form early and unconsciously, and strongly affect how the members will collaborate (Gersick, 1988). Recent research indicates that the planning of taskwork and teamwork can be very useful for collaboration and effectiveness in teams (Mathieu \& Rapp, 2009). 


\subsection{Team Design}

One of the biggest potential pitfalls for collaborative arrangements is the imbalance between the members (Haugland, 2004), which can be linked to various factors such as the amount of resources put into the collaboration, or one party being more dependent than others on the success of the collaboration. For example, studies of strategic alliances show that parties with relatively equal bargaining power - which is often determined by resource contribution - achieve a balanced power structure in which neither side appears to be dominant (cf. Yan \& Diao, 2003). A balanced structure will facilitate the involvement of all parties, thus contributing to a climate characterized by equality and trust (Li, Zhou, \& Zajac, 2009). In turn, this may contribute to a greater stability in the collaboration. The reasoning above can also be found in the team literature, in which parties who do not feel that their contribution is important typically experience a reduced motivation and commitment, which may then result in social loafing (see e.g. Karau \& Williams, 1993), i.e. parties make a smaller contribution to the group than they would if they were working individually.

Related to balance is the degree of stability, which is particularly important with regard to stability in the composition of the team. Changes in team composition can occur, both as new members join the operation and others leave. Such changes will affect the balance of power and increase the need for adaptation through the creation of (new) common standards and plans. Although teams that change the composition can be more creative than other teams (Nemeth \& Ormiston, 2007), in many cases a rather stable composition will be beneficial for both the collaboration and effectiveness of the team (e.g. see Akgün \& Lynn, 2002). In short, successful team design seems to be heavily based on a stability and balance between the members of the collaboration.

\subsection{Intragroup Conflicts}

We now turn to the role of intragroup conflicts, which are expected to play a vital role in the effectiveness of joint farming operations, as the move from traditional interdependent work to the interdependency of joint operations may be a troublesome transition. Therefore, intragroup conflict may be the key variable that links the effects of team planning and team design to the outcomes of joint operations (cf. Figure 1). The need for studying conflicts in these situations is also evident, since the literature on interorganizational relationships often ignores conflicts as micro mediating processes, while the literature on intragroup conflicts often ignores the complexity of the context and the dynamic nature of conflicts (e.g. Pelled, Eisenhardt, \& Xin, 1999).

Conflicts - defined as "a process that begins when an individual or group perceives differences and opposition between itself and another individual or group about interests or recourses, beliefs, values, or practices that matters to them" (De Dreu \& Gelfand, 2007, p. 6) - can differ in their content, direction and intensity. An important distinction in the literature on intragroup conflict is that of task conflict and relationship conflict. Task conflicts are disagreements among team members' ideas and opinions about the task being performed, while relationship conflicts are disagreements and incompatibilities among team members about issues that focus on personal issues (Jehn, Bezrukova, \& Thatcher, 2007).

The effects of relationship conflicts are consistently found to be detrimental to teams' performance and satisfaction (e.g. see the meta-analyses by De Dreu \& Weingart, 2003, and De Wit, Greer, \& Jehn, 2012). Relationship conflicts can cause severe negative processes that reduce cooperation, cohesion and coordination, and which derive energy that could be directed towards the fulfillment of the task (cf. Jehn et al., 2007). The effects of task conflicts are less clear, yet the general finding leans toward the negative side (De Dreu \& Weingart, 2003; De Wit et al., 2012). Nevertheless, there are some studies which show that task conflicts may be positive under some circumstances, e.g. a moderate amount of task conflicts can enhance innovation (De Dreu, 2006) and stimulate critical debate, thereby leading to better group decisions (Amason, 1996), though in short, "the positive effects of task conflicts are the exception rather than the rule" (Jehn et al., 2007, p. 181).

Importantly, the effects of conflicts on team performance and satisfaction are not only a function of the level and type of conflicts within the team, but also of how the conflicts are managed; thus, conflict management may act as a moderator as illustrated in Figure 1. Conflict management is what parties who experience conflicts "intend to do as well as what they actually do (Van de Vliert, 1997)" (De Dreu \& Gelfand, 2007, p. 30). Several conflict management strategies can be identified, e.g. integration, contending and avoidance, which are derived from the Dual Concern Model (Pruitt \& Rubin, 1986). Integration comprises problem-solving activities such as information exchange and active listening; contending comprises power-based activities such as aggressive behavior and pressure tactics; while avoidance means using withdrawal activities to escape a conflict situation. Not surprisingly, integration is superior to the other strategies in generating mutually-beneficial joint outcomes and satisfaction in most situations (e.g. De Dreu, Weingart, \& Kwon, 2000; Pruitt, 1981; Rognes \& Schei, 2010), 
although recent research indicates that teams with e.g. relationship conflicts may function better when these conflicts are avoided rather than being proactively managed (De Dreu \& Van Vianen, 2001; Jehn, 1997).

\section{Method}

\subsection{Sample}

We collected data from 10 collaborative farming operations in two geographic regions, consisting of five operations in each, which were selected by two advisers from the farming industry with extensive knowledge about the joint operations in their respective regions. Their criteria for selection were to pick some joint operations perceived to collaborate both well and not so well. This is consistent with the "polar types" technique recommended by Eisenhardt and Graebner (2007) in relation to maximizing variability in the data to explore contrasting patterns. In addition, we asked for joint operations that consisted of three or more members.

The selected joint operations were relatively large, and typically invested more than $\$ 1$ million in new cowsheds and technology. The number of members varied between three and five $(\mathrm{M}=3.8, \mathrm{SD}=0.8)$, the year of establishment varied from 2001 to $2007(\mathrm{M}=2004.3, \mathrm{SD}=2.2)$, milk quota per year varied from about 240,000 liters to approximately 664,000 liters $(M=470.000, S D=121.200)$, while technology varied between milking robots (six operations) and milking parlor (four operations). Importantly, none of these variables seemed to systematically vary with the other variables presented in this study.

\subsection{Interviews}

We interviewed 20 farmers: two individuals in each of the 10 joint operations. In each operation, we interviewed the administrator and one member suggested by the adviser, respectively. The interviews lasted between one and two hours, were all conducted by at least two interviewers from the research group, and always conducted at the farmer's site. Moreover, we were usually also allowed to inspect the farm and obtain first-hand impressions about the business and the context, and these observational data enhanced our understanding and interpretations. We tape-recorded and transcribed each of the interviews verbatim. Furthermore, we wrote down our reflections from the interviews and observations at the farm shortly after each interview, and subsequently held several presentations for farmers and representatives from the farming industry that allowed farmers to verify facts and contribute to interpretations, thereby strengthening the interpretive validity of our findings (Maxwell, 1992).

We used semi-structured interviews in this study (Saunders, Lewis, \& Thornhill, 2009), which implied that we had a list of topics or general questions prepared in advance, but that the participant could talk freely about the issues. The advantage of this method was that it can lead to information on matters/topics that the researchers had not thought of, but which can be of crucial importance to the research question (Saunders et al., 2009). We developed the interview guide based on what we thought would be relevant themes, with the main parts pertaining to how the joint operation was established and organized, and how team members collaborated, as well as their satisfaction about being in the operation.

\subsection{Coding}

The coding and interpretations of data were done by four coders: Coder A assessed the team planning process, Coders $\mathrm{B}$ and $\mathrm{C}$ jointly assessed the conflicts, whereas Coder $\mathrm{D}$ assessed the team design and the outcome variables (team performance and satisfaction). Coder A and Coders B/C used the program "Atlas.ti version 6.1", in their coding process to help with categorizing and analyzing the vast amount of data/quotes pertaining to their variables. The coding for the variables appearing in this study is briefly described below.

Team planning was coded as strong, medium or weak based on quotes describing how thoroughly the members had been in the selection of their partners, how well they had planned for the task work issue (goals, strategies, etc.) and how well they had planned for the teamwork (standards/norms, roles, etc.). Team design was coded as either being good, medium or poor based on the balance in the shares each of the members had in the joint operation, as well as on the stability of the parties being members of the joint operation, with inequality in shares and changing membership being indicators of a poor structure.

Conflicts were coded with regard to intensity (low, medium or high), type (task, relational) and management (integration, contending or avoidance). Conflict type was coded based on the definition of task and relationship conflicts mentioned earlier. Relationship conflicts were also further coded into status-, compatibility- or commitment conflicts (Bendersky, Befar, Weingart, Todorova, Bear, \& Jehn, 2010), but since this refined coding did not yield any substantial extra insights, we only report the results for the overall relationship conflict category. Conflict management was assessed based on quotes about how the parties behaved (e.g. aggressive, problem-solving, withdrawal) during the conflict process. 
Team satisfaction was coded as being high, medium or low based on quotes indicating the degree of a team member's expressed happiness at being a member of the joint operation. Team performance was assessed by three key indicators in joint farming operations: quota filling, milk per cow and fertility status. We attained these scores from the dairy organization to which the operations delivered their milk, and used the average scores for the period from 2008 to 2010 to assess performance. For each indicator, we ranked the joint operations from 1 to 10 , and then calculated the average rankings across the three indicators. Based on this, we reached a final ranking in which the joint operations clustered nicely into two categories, which were labelled high performers and low performers, respectively.

\section{Results}

The results from the coding process are summarized in Table 1. As can be seen from the table, there are high variance on all the variables, although some of the conflict variables (type and management) could not be assessed for joint operations A to E because the conflict intensity was too low. Nevertheless, looking at the patterns of the conflicts leads us to differentiate between three relatively distinct types of joint operations. Importantly, these three types also seem to be systematically related to input variables (team planning and team structure) and to output variables (team satisfaction and team performance). We label these three types of joint operations the Good (Joint Operation A-E), the Bad (Joint Operation F-G) and the Ugly (Joint Operation H-J).

Table 1. Key findings

\begin{tabular}{cccccccc}
\hline \multirow{2}{*}{$\begin{array}{c}\text { Joint } \\
\text { Operation }\end{array}$} & \multicolumn{2}{c}{ Input } & Team & Team & Conflict & Conflict & Conflict \\
Planning & Design & Intensity & Type & Team & Management \\
Satisfaction & Performance \\
\hline A & Strong & Good & Low & N/A & N/A & High & High \\
B & Strong & Good & Low & N/A & N/A & High & High \\
C & Strong & Good & Low & N/A & N/A & High & High \\
D & Strong & Good & Low & N/A & N/A & High & High \\
E & Strong & Good & Low & N/A & N/A & High & Low \\
F & Medium & Medium & Medium & Task & Avoidance & Medium & Low \\
G & Medium & Good & Medium & Task & Avoidance & Medium & Low \\
H & Weak & Poor & High & Relational & Contending & Low & Low \\
I & Weak & Poor & High & Relational & Contending & Low & Low \\
J & Weak & Poor & High & Relational & Contending & Low & High \\
\hline
\end{tabular}

Note: N/A = Not Applicable

\subsection{The Good Operations}

The first class of joint operations is the five teams A to E, all of which are characterized by low levels of conflict. The teams in this Good group are also remarkably consistent in relation to the input variables; all having strong team planning and good team design (see Table 1). Hence, they have paid a sufficient amount of attention to team planning (e.g. discussing goals, expectations, collaboration issues, etc.) before entering into the joint operation, and have a rather balanced power structure and high stability in their membership. The informants in the Good category group emphasize the importance of team planning, as one express it:

- It is like putting a seed in the ground, it takes some time before it starts to grow. It needs some time to work its way up. Maybe it becomes clear that, no, this is not working, we don't want this. And that is a bit late if the building is already there. So we used some years for planning. (Leader, JO B)

Others underscore the importance of selecting the right partners, and that this may also occasionally take some time: 
- There was a man who said that it is harder to find an appropriate partner for a joint farming operation than it is to find a wife. (Member, JO D)

- Consider very closely who you collaborate with. Know each other well. (Leader, JO D)

- It is important that you have some time to grow together, and that the platform for cooperation is there. And that you know those you are going to collaborate with very well. (Leader, JO B)

The Good joint operations also did very well on the output measures. Four of the five teams were high performers, with the only exception being Joint Operation E. In fact, operation E had the lowest performance score of all the 10 joint operations; however, all five Good operations were quite satisfied with their team.

\subsection{The Bad Operations}

The second class of joint operations consists of the two teams F and G, both of which were characterized by moderate levels conflicts being predominantly task related (see Table 1). Furthermore, they both choose avoidance as their conflict management approach. The leader of joint operation $\mathrm{G}$ describes a typical conflict situation arising due to different standards in work performance:

- It is irritating when I work day and night for a week and then return after three weeks to my next shift, just to see that the effort I put in hasn't paid off because the things I started haven't been followed up on by the others, and I have to start all over again. (Leader, JO G)

And when later asked about how they managed conflicts, he emphasized the avoiding tendency:

- I think we are quite bad in speaking up to the person we should address. We just talk in general terms. We are too shy about conflicts. (Leader, JO G)

The two Bad operations are also quite consistent on the input variables, scoring medium on team planning and medium and good on team design. For example, in Joint Operation F they had a shift in membership, and the new female member of the joint operation describes how this could be a challenge for the team design:

- The worst thing being in a joint farming operation is that the other members cannot handle the fact that I can also do things ... it's a bit like girls cannot do these kinds of things... I just have to do things and then they gradually realize that I am capable of doing them. (Member, JO F)

Regarding the planning of the collaboration, the leader of Joint Operation G pointed to the need for better planning than they had done themselves before they founded their operation:

- It is important to talk a lot together and get to know each other well, and talk more about the objectives and the day to day running of the business ... to discuss this much more thoroughly than we did before the start-up. (Leader, JO G)

Finally, looking at the output of the teams in the Bad category, these joint operations had a low performance score and only a medium team satisfaction.

\subsection{The Ugly Operations}

The third class of operations consists of the three remaining teams, H, I and J. These teams are characterized by high conflict intensity and primarily relationship types of conflicts (see Table 1). All three operations also regularly used contending behavior as their main conflict management approach, and two informants in the Ugly operations illustrated relationship conflicts in this way:

- I felt more and more that what I did was criticized. I felt all the time that I didn't do it the way they wanted me to do it. In fact, he was after us even when it was regarding insemination. The timing was wrong, and wrong and wrong and wrong. And then I said, but I have done this for 30 years and in fact succeeded (Member, JO H)

- There is at least one person clearly stating that he does as he likes ... so he and the leader have not been on speaking terms for the last year... it is a pity, because they are bursting full of anger. (Member, JO I)

These informants also tell about how domination and even threats are part of the conflict management approach by those in this Ugly joint operation:

- He clenched his fist in my face a few times. (Member, JO I).

- And then he says that if I don't get my will on this, I will just walk away... He has said this several times; that we will have to continue on our own, because he knows that we are dependent on him. So it is not that easy. (Member, $\mathrm{JO} \mathrm{H}$ ) 
The Ugly operations are also very consistent with regard to team planning and team structure, (and clearly different from the Good and the Bad category operations); the Ugly operations entered their joint operations without sufficient team planning and/or experienced changes in memberships. For example, some informants stated:

- The process went a bit hasty. We didn't sit down and discuss things up-front. That goes for both the construction process and for the collaboration. We should also have discussed the cooperation routines a bit more. (Member, JO J)

- No, I must say that we didn't discuss that [norms/rules] much. We probably believed that the agreement was comprehensive. (Member, $\mathrm{JO} \mathrm{H}$ )

Not surprisingly, the Ugly teams were dissatisfied with their teams. Two of the three teams in the Ugly category ( $\mathrm{H}$ and $\mathrm{I}$ ) were also low performers, yet interestingly team J performed quite well. Looking at the data, joint operation $\mathrm{J}$ seemed to perform quite well because one very competent person had the major responsibility for running the operation (i.e. a one-person team), though at the cost of a cooperative climate.

\section{Discussion}

The goal of this study was to address the question of why some joint farming operations succeed and other fail. Indeed, our consistent pattern of results indicates that careful planning and balanced structures seem to limit the conflict intensity to a minimum, which in turn is associated with team satisfaction and high performance. Our results point to at least three implications: preparations are important, conflicts are challenging and effects are not deterministic. We discuss these below.

\subsection{Implications}

First, our findings highlight the potential value of carefully preparing a collaborative effort. The value of this stage was heavily stressed by several of our informants, yet the critical factor seems not to be the time used on planning per se, but rather what was done. In the joint farming operations in our study, the one important issue to agree on was shared standards, i.e. the level of quality in the completion of various duties such as the cleaning of the milk robot. This finding is consistent with recent research on team foundations, in which these types of discussions are suggested (e.g. Mathieu \& Rapp, 2009). Moreover, a practical implication of this is that teams such as the ones in our study may benefit from creating a team contract (e.g. Norton \& Sussman, 2009). Such a contract need not be written, but is intended to help the group agreeing on how they will work together. One factor that can be included is to establish common standards, and to discuss such matters generates a better understanding of mutual obligations and expectations.

Second, our results indicate that conflicts are challenging. Joint operations experiencing conflicts generally scored lower than those that did not experience such conflicts, which may lead us to conclude that conflicts in general are bad, especially with regard to relationship conflicts. However, we should be careful with this conclusion because the "idea that relationship conflicts ... are harmful can let people believe that the negative effects of conflicts are inherent in the conflicts themselves" (Tjosvold, 2007, p. 449). This points to how conflicts are managed, and as is evident from our findings, none of the five joint operations with medium- or high conflict intensity used the recommended integrative approach. Therefore, although our results undoubtedly point to the negative effects of conflicts, appropriate conflict management may have somewhat countered this conclusion. As one example, we do believe that the teams in the "Bad" category above had the potential to be successful if they could manage their conflicts more actively (e.g. integration).

Third, the relationship between the variables in our studies is not deterministic. Thus, even if everything is done "right" this does not guarantee a good result, as is evident from joint operation E. Conversely, even if everything is done "wrong" this does not completely rule out the possibility of success, as is evident with joint operation J. Nevertheless, we may speculate how long the team in the latter operation can be sustained under the current conflict pressure. This also points to the need for further studies than can examine conflict processes and conflict management, in addition to their effects over time.

\subsection{Considerations}

Obviously, there are several limitations in the present research that future research should address. First, the interviews were retrospective and participants may have had selective memory in describing and interpreting previous behavior in hindsight. Moreover, the direction of causality is open to speculation, and alternative explanations for our results cannot be ruled out. Additionally, our sample of joint operations is not a representative one, but instead was selected to maximize the variability on the main variables in the study. 
That being said, our study also has several strengths that should be emphasized. For example, using an objective performance measure based on three indicators of productivity and quality over a three-year period enhanced the credibility of the study. Furthermore, using different coders on different variables increased the independency between the coded variables.

\section{Conclusion}

This study is among the first to address how those used to working independently may overcome obstacles when moving into interdependent arrangements. This ability to join such collaborations is an important skill, as the need for cooperation seems to be ever-increasing as individuals and organizations constantly seek resources and a competitive advantage. Indeed, our results indicate that "lonely riders" - those used to working independently - may become "three musketeers" and work effectively together as a team. However, successful cooperation seems to require that the parties invest their efforts in the collaboration.

\section{Acknowledgements}

This project is supported by TINE AS and The Research Council of Norway. We wish to thank Hedvig Røsberg Gjerde, Håvard Hagen, Siri Kamøy and Karen Sofie Grung Smedberg for their help with the coding and interpretation of the data.

\section{References}

Akgün, A. E., \& Lynn, G. S. (2002). Antecedents and consequences of team stability on new product development performance. Journal of Engineering and Technology Management, 19, 263-286. http://dx.doi.org/10.1016/S0923-4748(02)00021-8

Amason, A. C. (1996). Distinguishing the effects of functional and dysfunctional conflict on strategic decision making. Resolving a paradox for top management groups. Academy of Management Journal, 39, 123-148. http://www.jstor.org/stable/256633

Bamford, J., Ernst, D., \& Fubini, D. (2004). Launching a world-class joint venture. Harvard Business Review, 82, 90-101.

Bendersky, C., Behfar, K., Weingart, L. R., Todorova, G., Bear, J., \& Jehn, K. A. (2010). Revisiting the dimensions of intragroup conflict: Theoretical and psychometric construct refinement. Paper presented at the International Association for Conflict Management conference, Boston, USA.

De Dreu, C. K. (2006). When too little or too much hurts: Evidence for a curvilinear relationship between task conflict and innovation in teams. Journal of Management, 32, 83-107. http://dx.doi.org/10.1177/0149206305277795

De Dreu, C. K., \& Gelfand, M. J. (2007). Conflict in the workplace: Sources, functions and dynamics across multiple levels of analysis. In C. K. De Dreu, \& M. J. Gelfand (Eds.). The psychology of conflict and conflict management in organization (pp. 3-54). New York: Taylor \& Francis Group.

De Dreu, C. K., \& Van Vianen, A. E. (2001). Managing relationship conflict and the effectiveness of organizational teams. Journal of Organizational Behavior, 22, 309-328. http://dx.doi.org/10.1002/job.71

De Dreu, C. K., Weingart, L. R. (2003). Task versus relationship conflict, team performance, and team member satisfaction: A meta-analysis. Journal of Applied Psychology, 88, 741-749. http://dx.doi.org/10.1037/0021-9010.88.4.741

De Dreu, C. K., Weingart, L. R., \& Kwon, S. (2000). Influence of social motives on integrative negotiation: A meta-analytic review and test of two theories. Journal of Personality and Social Psychology, 78, 889-905. http://dx.doi.org/10.1037/0022-3514.78.5.889

De Wit, F. R., Greer, L. L., \& Jehn, K. A. (2012). The paradox of intragroup conflict: A meta-analysis. Journal of Applied Psychology, 97, 360-390. http://dx.doi.org/10.1037/a0024844

Eisenhardt, K. M., \& Graebner, M. E. (2007). Theory building from cases: Opportunities and challenges. Academy of Management Journal, 50, 25-32.

Gersick, C. J. (1988). Time and transition in work teams: Toward a new model of group development. Academy of Management Journal, 31, 9-41. http://dx.doi.org/10.2307/256496

Guttman, H. M. (2008). Great business teams: Cracking the code for standout performance. Hoboken: Wiley.

Haugland, S. A. (2004). Samarbeid, allianser og nettverk (in Norwegian, 2nd edition). Oslo: Universitetsforlaget. 
Jehn, K. A. (1997). A qualitative analysis of conflict types and dimensions in organizational groups. Administrative Science Quarterly, 42, 520-557. http://dx.doi.org/10.2307/2393737

Jehn, K. A., Bezrukova, K., \& Tachter, S. (2007). Conflict, diversity and faultlines in workgroups. In C. K. De Dreu, \& M. J. Gelfand (Eds.). The psychology of conflict and conflict management in organization (pp. 179-210). New York: Taylor \& Francis Group.

Karau, S. J., \& Williams, K. D. (1993). Social loafing: A meta-analytic review and theoretical integration. Journal of Personality and Social Psychology, 65, 681-706. http://dx.doi.org/10.1037//0022-3514.65.4.681

Katzenbach, J. R., \& Smith, D. K. (1993a). The discipline of teams. Harvard Business Review, 71, 111-120.

Katzenbach, J. R., \& Smith, D. K. (1993b): The wisdom of teams: creating the high-performance organization. Boston, Mass: Harvard Business School Press.

Li, J., Zhou, C., \& Zajac, E. (2009). Control, collaboration and productivity in international joint ventures: Theory and evidence. Strategic Management Journal, 30, 865-884. http://dx.doi.org/10.1002/smj.771

Mathieu, J. E., \& Rapp, T. L. (2009). Laying the foundation for successful team performance trajectories: The roles of team charters and performance strategies. Journal of Applied Psychology, 94, 90-103. http://dx.doi.org/10.1037/a0013257

Mathieu, J. E., \& Schulze, W. (2006). The influence of team knowledge and formal plans on episodic team process-performance relationships. Academy of Management Journal, 49, 605-619.

Maxwell, J. A. (1992). Understanding and validity in qualitative research. Harvard Educational Review, 62, 279-300.

Mendzela, E. (1997). Effective teams. CPA Journal, 67, 62-63.

Nemeth, C. J., \& Ormiston, M. (2007). Creative idea generation: Harmony versus stimulation. European Journal of Social Psychology, 37, 524-535. http://dx.doi.org/10.1002/ejsp.373

Norton, W. J., \& Sussman, L. (2009). Team charters: Theoretical foundations and practical implications for quality and performance. The Quality Management Journal, 16, 7-17.

Pelled, L. H., Eisenhardt, K. M., \& Xin, K. R. (1999). Exploring the black box: An analysis of work group diversity, conflict and performance. Administrative Science Quarterly, 44, 1-28. http://dx.doi.org/10.2307/2667029

Pruitt. D. G. (1981). Negotiation behavior. New York: Academic Press.

Pruitt, D. G., \& Rubin, J. Z. (1986). Social conflict: Escalation, stalemate, and settlement. New York: McGraw-Hill.

Rod, M. (2009). A Model for the Effective Management of Joint Ventures: A Case Study Approach. International Journal of Management, 26, 3-17.

Rognes, J. K., \& Schei, V. (2010). Understanding the integrative approach to conflict management. Journal of Managerial Psychology, 25, 82-97. http://dx.doi.org/10.1108/02683941011013885

Saunders, M. N., Lewis, P., \& Thornhill, A. (2009). Research methods for business students (5th edition). Essex: Pearson Education.

Thompson, L. L. (2008). Making the team: A guide for managers (3rd edition). Upper Saddle River, NJ: Prentice Hall.

Tjosvold, D. (2007). Conflicts in the study of conflict in organizations. In C. K. De Dreu, \& M. J. Gelfand (Eds.). The psychology of conflict and conflict management in organization (pp. 445-454). New York: Taylor \& Francis Group.

Van de Vliert, E. (1997). Complex interpersonal conflict behavior: Theoretical frontiers. Hove, UK: Psychology Press.

Williams, R. G., \& Lilley, M. M. (1993). Partner selection for joint-venture agreements. International Journal of Project Management, 11, 233-237.

Wittmann, C. M. (2007). Strategic alliances: What can we learn when they fail? Journal of Business-to-Business Marketing, 14, 1-19. http://dx.doi.org/10.1300/J033v14n03_01

Yan, A., \& Diao, J. (2003). Interpartner fit and its performance implications: A four-case study of U.S.-China joint ventures. Asia Pacific Journal of Management, 20, 541-564. 